\title{
Virtual Machine Consolidation using Load Balancing algorithm in Cloud Data Center
}

\author{
Manjushri S. Masane ${ }^{1}$, N. P. Kulkarni ${ }^{2}$ \\ ${ }^{1}$ Department of Information Technology, Smt. Kashibai Navale Collage of Engineering, Pune, India \\ ${ }^{2}$ Professor, Department of Information Technology, Smt. Kashibai Navale Collage of Engineering, Pune, India
}

\begin{abstract}
Cloud computing has transformed the Information and Communication Technology (ICT) industry by enabling on-demand provisioning of flexible computing resources on a pay-as-you-go basis. Cloud computing has resulted in the establishment of large-scale data centers around the world containing thousands of compute nodes. However, Cloud data centers consume huge amounts of electrical energy resulting in high operating costs and carbon dioxide $\left(\mathrm{CO}_{2}\right)$ emissions to the environment. Green Cloud is an advanced scheduling scheme to reduce energy consumption. Green cloud computing is growing need in industries. To address the problem of high energy use, it is necessary to eliminate inefficiencies and waste in the way electricity is delivered to computing resources, and in the way these resources are utilized to serve application workloads. Previously Ant Colony System used for dynamic VM consolidation, and this system using more resources. In this paper, a new proposed architecture is implemented for VM consolidation and which uses minimum resources and decision taken by system is minimum than previous algorithm. The aim of new system is that, it is used for minimize energy consumption.
\end{abstract}

Keywords: VM Consolidation; Green Cloud Computing; Virtualization; Energy Consumption

\section{Introduction}

Cloud computing is related with a new paradigm for provisioning different computing resources, usually addressed from three primary aspects: Infrastructure as a Service (IaaS), Platform as a Service (PaaS) and Software as a Service (Sass). Green cloud computing is virtualized computing platform and it is scalable use of computing resources.

Cloud services allow individuals and businesses to use software and hardware that are managed by third parties at remote locations. The deployment models are categorized into public, private, community, and hybrid Clouds. The characteristics include on-demand self-service, broad network access, resource pooling, rapid elasticity, and measured service.

Dynamic Consolidation of Virtual Machines (VMs) gives a significant opportunity to save the energy by turning off unused Physical Machines (PMs) in a Data Centers. To create an efficient cloud computing system which utilizes the strengths of the cloud is need.

Green cloud computing (GCC) can use to achieve this purpose. GCC is efficient processing and utilization of cloud computing infrastructure which minimize energy consumption. High-energy consumption leads to high operational cost, which reduces the profit margin of cloud providers. In the ACS system, Dynamic VM consolidation is another effective way to improve the utilization of resources and their energy-efficacy. The sharing of the PM resources among multiple VMs is handled by the Virtual Machine Monitor (VMM).

In the previous work, address the VM consolidation problem with the objective to reduce energy consumption of data centers, a distributed system architecture used to perform dynamic VM consolidation to improve resource utilizations of PMs and to reduce their energy consumption. Also propose a dynamic VM consolidation approach that uses a highly adaptive online optimization metaheuristic algorithm called Ant Colony System (ACS) [1] to optimize VM placement. In this system when global manager gives response to the user, it takes more time. So the new Load Balancing algorithm achieve average access time, resource utilization and energy consumption.

\section{Related Work}

Cloud computing can consume more energy than traditional computing. Even with energy saving techniques such as server virtualization and advanced cooling systems, cloud computing is not always the greenest computing technology [2]. Cloud computing can be seen as efficient processing and resource utilization of resources while minimizing the energy consumptions. Otherwise, growing demand of cloud computing may increase in huge energy consumption. Using all the properties of cloud computing, GCC ensures that the future growth of cloud is environmentally sustainable and minimize the energy consumption of cloud and its components.

F. Farahnakian[1] proposed approach for VMs problems in Green Cloud. Overall due to the ever-increasing cloud infrastructure demand, there has been a significant increase in the size and energy consumption (EC) of the cloud data centers. High energy consumption not only translates to a high operating cost, but also leads to higher carbon emissions. Therefore, energy-related costs and environmental impacts of data centers have become major concerns and research communities are being challenged to find efficient energy-aware resource management strategies. Maintains the desired QoS is an important requirement for cloud data center. The QoS requirements are formated via Service Level Agreements (SLAs) that describe the required 


\section{International Journal of Science and Research (IJSR) \\ ISSN (Online): 2319-7064}

Index Copernicus Value (2015): 78.96 | Impact Factor (2015): 6.391

performance levels, such as minimal throughput and maximal response time.

Anton Beloglazov and R. Buyya [3] presented the managing overloaded hosts for VMs consolidation in cloud data centers. Cloud computing has reform the ICT industry by enabling on-demand provisioning of computing resources based on a pay-as-you-go model. An organization can either outsource its computational needs to the Cloud avoiding high up-front investments in a private computing infrastructure and consequent. maintenance costs, or implement a private Cloud data center to improve the resource management and provisioning processes. The main problem of data centers is high energy consumption, which has risen by $56 \%$ from 2005 to 2010 , and in 2010 accounted to be between $1.1 \%$ and $1.5 \%$ of the global electricity use, Apart from high operating costs, this results in substantial carbon emissions, which are estimated to be $2 \%$ of the global emissions.

J. Huang, M.Moh [4] obtainable dynamic heuristic VM migration and consolidation approach. The energy consumption is modeled as the sum of execution energy, communication energy during VM migration, and servers switching energy. Cloud computing delivers a pool of preoccupied and virtualized resources, including computing power, storage, platforms and software applications over the Internet based on users demand.

Live VM migration technology is the significant application and embody of the flexibility and availability of VM technology [5]. Currently, live migration is widely used for the maintenance management in virtualized cloud computing data centers. When the workload of some host is too heavy, we can move its VMs which are providing services to an idle host to achieve load balance through live migration.

Zenon Chaczko. et. al [6] gives an idea about the basic concepts of Cloud Computing and Load balancing availability and load balancing in cloud Computing.

Srikantaiah et al. [7] have studied the problem of request scheduling for multi-tier web-applications in virtualized heterogeneous systems to minimize energy consumption, while meeting performance requirements.

Virtualization [8] is becomes most powerful technology in data centers and cloud computing. One of the main benefits of virtualization is Dynamic VM Consolidation (DVMC) that is used by data centers to reduce energy consumption. DVMC uses live migration ability that is provided by virtualization technology for transferring a running VM from one host to another.

Following table 1 shows that the summery of existing papers.

Table 1: Comparison of Existing Techniques

\begin{tabular}{|c|c|c|c|c|}
\hline $\begin{array}{l}\text { Sr. } \\
\text { No }\end{array}$ & Paper Name & $\begin{array}{c}\text { Technique } \\
\text { Used }\end{array}$ & Advantages & Limitation \\
\hline 1 & $\begin{array}{l}\text { Energy-Aware } \\
\text { Dynamic VM } \\
\text { Consolidation } \\
\text { in Cloud Data } \\
\text { Centers Using }\end{array}$ & $\begin{array}{l}1 . \\
\text { Distributed } \\
\text { Controller } \\
\text { 2. Ant } \\
\text { Colony }\end{array}$ & $\begin{array}{l}\text { To solve VM } \\
\text { consolidation } \\
\text { problem and } \\
\text { reduce Energy } \\
\text { consumption }\end{array}$ & $\begin{array}{l}\text { VM } \\
\text { consolidation } \\
\text { is up to } \\
\text { working with } \\
\text { limited }\end{array}$ \\
\hline
\end{tabular}

\begin{tabular}{|c|c|c|c|c|}
\hline & $\begin{array}{l}\text { Ant Colony } \\
\text { System [2] }\end{array}$ & System & & server \\
\hline 2 & $\begin{array}{c}\text { Utilization } \\
\text { Prediction } \\
\text { Aware VM } \\
\text { Consolidation } \\
\text { Approach for } \\
\text { Green Cloud } \\
\text { Computing[4] }\end{array}$ & \begin{tabular}{|l|} 
1.Dynamic \\
VM \\
Consolidatio \\
$n$
\end{tabular} & $\begin{array}{c}\text { UP-BFD } \\
\text { enables } \\
\text { proactive } \\
\text { consolidation } \\
\text { of VMs using } \\
\text { a resource } \\
\text { utilization } \\
\text { prediction } \\
\text { model. } \\
\end{array}$ & $\begin{array}{l}\text { This approch } \\
\text { not predicted } \\
\text { for VM to } \\
\text { become } \\
\text { overloaded in } \\
\text { the near } \\
\text { future. }\end{array}$ \\
\hline 3 & $\begin{array}{c}\text { Modeling and } \\
\text { Analysis of } \\
\text { State-of-the- } \\
\text { Art VM-Based } \\
\text { Cloud } \\
\text { Management } \\
\text { Platforms[7] }\end{array}$ & $\begin{array}{l}\text { Cloud Mgmt } \\
\text { platforms: } \\
\text { 1)Eucalyptu } \\
\text { s, } \\
\text { 2) Open } \\
\text { Nebula, and } \\
\text { 3) Nimbus }\end{array}$ & $\begin{array}{c}\text { It influences } \\
\text { the choice of } \\
\text { selecting a } \\
\text { particular } \\
\text { system for a } \\
\text { private cloud } \\
\text { is the level of } \\
\text { customization }\end{array}$ & \begin{tabular}{|c|} 
Those model \\
are correct \\
and feasible \\
as the \\
numbers of \\
VM grow but \\
not for big \\
platform.
\end{tabular} \\
\hline 4 & $\begin{array}{l}\text { A Progress } \\
\text { Management } \\
\text { System for } \\
\text { Live Virtual } \\
\text { Machine } \\
\text { Migration } \\
\text { in Cloud } \\
\text { Computing }\end{array}$ & $\begin{array}{l}\text { Pacer, is a } \\
\text { tool which } \\
\text { accurately } \\
\text { predicts the } \\
\text { migration } \\
\text { time. }\end{array}$ & $\begin{array}{c}\text { The stateful } \\
\text { server keeps } \\
\text { records of the } \\
\text { state of the } \\
\text { clients from } \\
\text { one request to } \\
\text { the next } \\
\text { request. }\end{array}$ & \begin{tabular}{|} 
Extending \\
Pacer to \\
analyze and \\
model the \\
behavior of \\
complex \\
enterprise \\
applications.
\end{tabular} \\
\hline 5 & $\begin{array}{c}\text { Virtual } \\
\text { Machines } \\
\text { Migration } \\
\text { based on } \\
\text { Greedy } \\
\text { Algorithm in } \\
\text { Cloud } \\
\text { Computing }\end{array}$ & $\begin{array}{l}\text { Greedy } \\
\text { algorithm }\end{array}$ & $\begin{array}{l}\text { It saves } \\
\text { energy at } \\
\text { server side } \\
\text { PM and } \\
\text { reduce total } \\
\text { migration } \\
\text { time }\end{array}$ & \begin{tabular}{|c|} 
To improve \\
greedy \\
algorithm \\
which is used \\
for large \\
setup
\end{tabular} \\
\hline
\end{tabular}

\section{Proposed Methodology}

This section describes the detailed implementation of a tool as follows.

\section{A. System Framework}

The overall working of the proposed system is used for minimize energy consumption, CPU utilization, dynamic consolidation and transferring the load on another idle physical machine which is shown in fig 1 . 


\section{International Journal of Science and Research (IJSR) \\ ISSN (Online): 2319-7064}

Index Copernicus Value (2015): 78.96 | Impact Factor (2015): 6.391

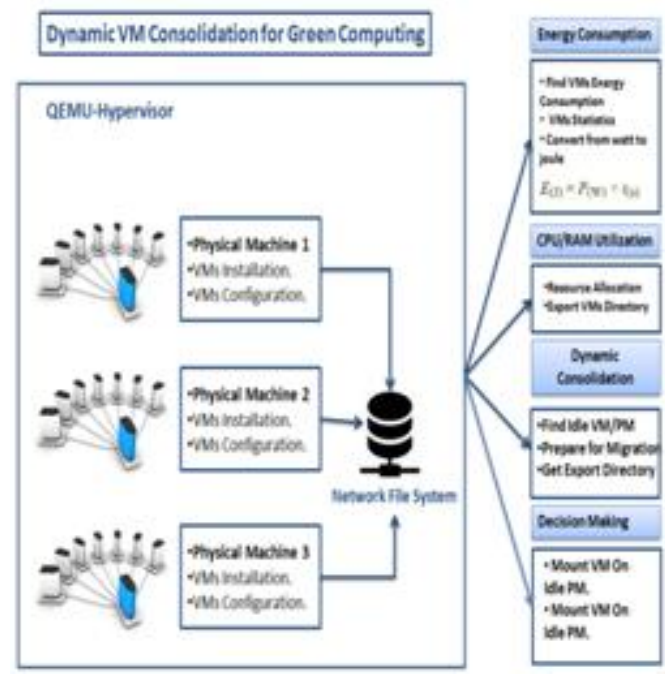

Figure 1: Proposed System for Dynamic VM Consolidation

Public Cloud is used for this system, in this system two physical machines are connected via network. One physical machine including two VM's are installed. The QEMU is a Hypervisor which is used for monitoring Virtual Machine. There are two major function in this system is Energy consumption and dynamic consolidation. A hypervisor is piece of computer software or hardware that creates and runs virtual machine. Network file system is used for transferring the data on network. Attribute Data Collector: It will collect CPU Utilization, RAM Utilization and Reply time 3 attributes from each VMs. RAM Utilization and CPU Utilization can be calculated based on the built-in system functionality. (Example Java has classes for system utilization).

\section{- Energy Consumption:}

Find VM Energy Consumption of the System and then status of Physical Machine. In that calculate total energy of physical machine.

\section{- CPU Utilization:}

Determine CPU utilization by using

virt-top command.

Total capacity $=250$ watt

For calculating PM utilisation i.e equal to the VMs utilisation in physical host.

\section{- Dynamic Consolidation:}

When VM is overloaded that time find out another physical machine for transferring load.

\section{- Load balancer}

It will categorize all the client requests and dequeue the appropriate request to Load Balancer. It checks status of VM underload or overload using load balancing algo. Then it will give system status to machine for migration otherwise shut off VM for energy saving.

\section{- Decision Making:-}

Transferring the overloaded PM on another Physical machine.

\section{B. Algorithm for VM load Balancing}

Load Balancer checks status of VM underload or overload using load balancing algo. Then it will give system status to machine for migration otherwise shut off VM for energy saving. It is shown as below in algorithm 1:

Algorithm 1: Virtual Machine Load Balancing

$\mathrm{C}=\mathrm{CPU}$ usage

$\mathrm{M}=$ Memory usage

$\mathrm{I}=$ Input :- generate load

$\mathrm{O}=$ Output :- migrate load

Step1: Clients send service requests to Cloud

Step 2: Total CPU usage $>=$ threshold CPU usage then check Virtual Machine status //overloaded// Step 3: Total CPU usage $<=$ threshold CPU usage then check Virtual machine status //underloaded//

Step 4: VM will going to overload then forward this request to Load Balancer.

Step 5: Migrate VM on ideal Physical machine.

Load balancing algorithm which is build for maintaining load on physical machine and minimize energy consumption. In this algorithm the steps are going to threshold values.

\section{Results and Discussion}

Experimental evaluation is carried on system which Physical Machine CPU utilisation. Proposed system is developed on java based on linux cent os 7 which uses Netbeans as IDE. System is put VMs on physical host which carries load of the system. Following results shows that Physical machine usages, and its energy consumption in percent and it is converted into watt.

To create VMs software VMware is installed. To prove the heterogeneity of the system we used linux server and Centos7 Linux for deployment of the system. After analysis and experiment, we set Thersholdmax $=80 \%$ and Thersholdmin $=30 \%$ for better results.

Table 1: Physical Machine Consumption

\begin{tabular}{|c|l|c|c|c|}
\hline Sr.No & Host Name & $\begin{array}{c}\text { PM Total } \\
\text { Usage(\%) }\end{array}$ & $\begin{array}{c}\text { VM 1 } \\
\text { Usage } \\
(\%)\end{array}$ & $\begin{array}{c}\text { VM 2 } \\
\text { Usage } \\
(\%)\end{array}$ \\
\hline 1 & manju.project.com & 20.1 & 0 & 20.14 \\
\hline 2 & manju.project.com & 50.3 & 30.2 & 20.01 \\
\hline 3 & manju.project.com & 40.196 & 40.196 & 0 \\
\hline 4 & manju.project.com & 36.5 & 31.531 & 4.978 \\
\hline 5 & manju.project.com & 61.45 & 36.31 & 25.14 \\
\hline 6 & manju.project.com & 16.28 & 14.199 & 2.028 \\
\hline 7 & manju.project.com & 55.08 & 38.53 & 16.55 \\
\hline 8 & manju.project.com & 66.34 & 42.16 & 24.18 \\
\hline 9 & manju.project.com & 85.64 & 61.04 & 24.60 \\
\hline 10 & manju.project.com & 85 & 85.061 & 0 \\
\hline
\end{tabular}

Table 1 shows total usage of PM total usage which is equal to the two VM usage. 


\section{International Journal of Science and Research (IJSR) \\ ISSN (Online): 2319-7064}

Index Copernicus Value (2015): 78.96 | Impact Factor (2015): 6.391

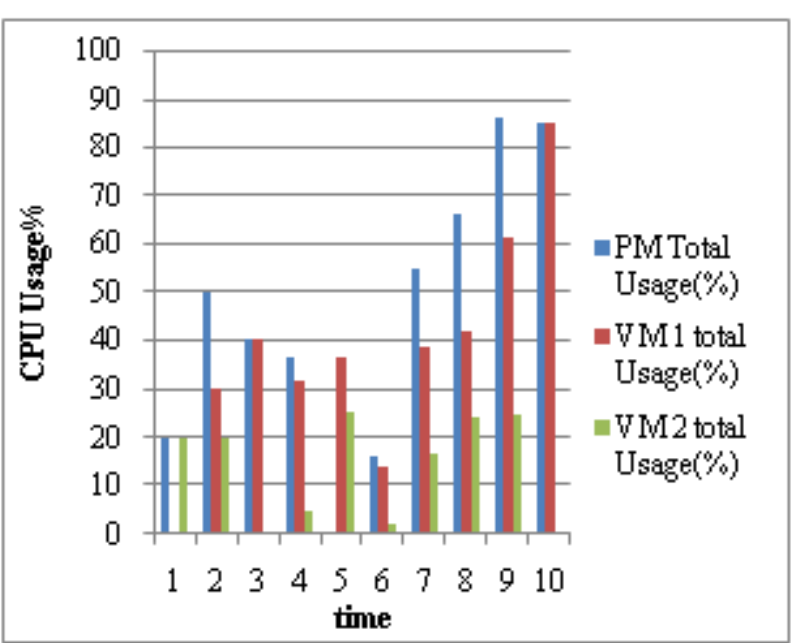

This fig. shows that CPU utilisation of physical host which is the addition of two VMs usage

$\mathrm{PM}_{\text {usage }}=\mathrm{VM} 1_{\text {usage }}+\mathrm{VM} 2_{\text {usage }}$

The following fig shows that Physical Machine Energy Consumption

Figure 2: Physical machine CPU usage in \%

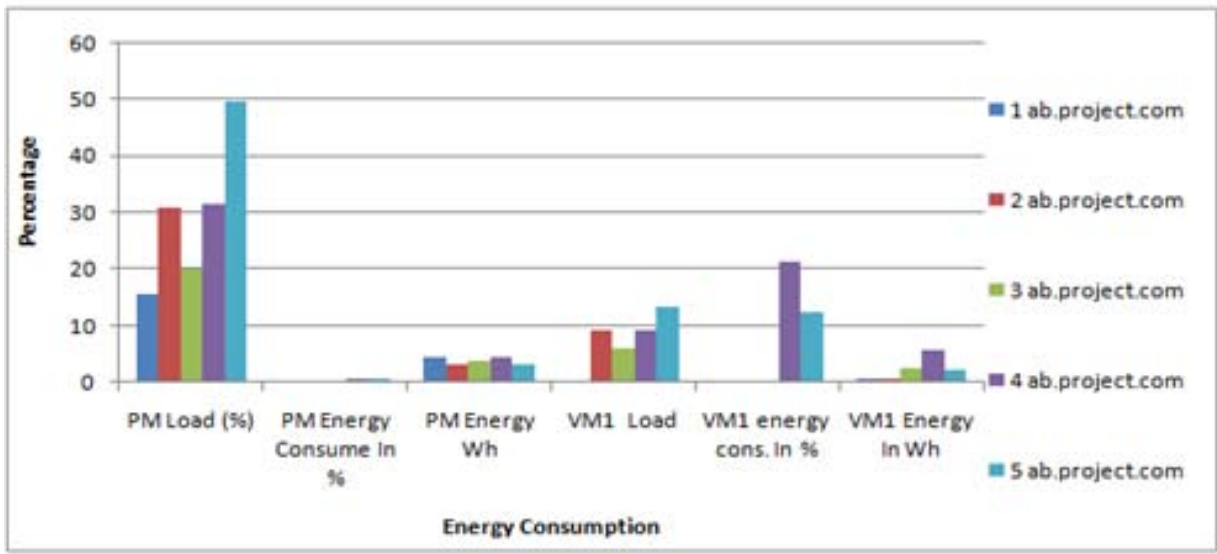

Figure 3: Physical Machine Energy Consumption

Fig 3 shows that when two physical host are connected in the network.

Total Capacity $=250$ watt

Total CPU-usage $=15.5 \%$

Total Energy -usage $=27 \%$

Then $250 / 15.5=16.1290$

$16.1290 * 27 / 100=4.35 \mathrm{Wh}$

When that first PM is used for processing and this is used how many load and how many energy is consumed for this load in percent.

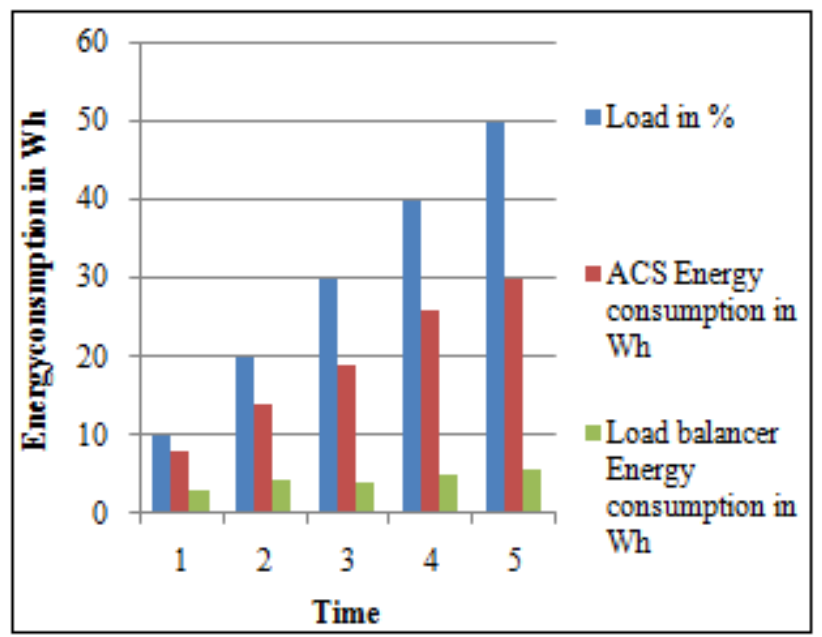

Figure 4: Energy Consumption of Ant colony Algo. Vs Load balancing algorithm.
The main comparison is shown in below fig. 4. This fig shows the energy consumption of existing algorithm is greater than proposed algorithm.

\section{Conclusion and Future Scope}

An Proposed system is used for VM migration on another ideal PM using Load balancing algorithm. Dynamic VM consolidation reduces the energy consumption of data centers by consolidating VMs into a reduced number of active Physical Machines while preserving Quality of Service requirements. Due to this system resources are minimized and time is less for taking decisions.

The proposed VM consolidation system give importance to minimize energy consumption and load balancing of a Physical Machines. Future scope is that we can extend this system for large data centers and Organization also system can be extension of the VM manager within the Open Stack Cloud Platform.

\section{References}

[1] Fahimeh Farahnakian, Adnan Ashraf, Tapio Pahikkala, Member, Pasi Liljeberg, and Hannu Tenhunen and Hannu Tenhunen, Member," Using Ant Colony System to ConsolidateVMs for Green Cloud Computing" Ieee Transactions on Services Computing, vol. 8, no. 2, March/April 2015. 


\section{International Journal of Science and Research (IJSR) \\ ISSN (Online): 2319-7064}

Index Copernicus Value (2015): 78.96 | Impact Factor (2015): 6.391

[2] Anton Beloglazov and Rajkumar Buyya," Managing Overloaded Hosts for Dynamic Consolidation of Virtual Machines in Cloud Data Centers Under Quality of Service Constraints" IEEE Transactions on Parallel and distributed systems, vol. 24, no. 7, July 2013.

[3] Saurabh Kumar Garg and Rajkumar Buyya, 2012. "Green Cloud computing and Environmental Sustainability," Harnessing Green IT: Principles and Practices edited by San Murugesan and G. R. Gangadharan, John Wiley \& Sons, Ltd.

[4] Jing Huang, Kai Wu, and Melody Moh," Dynamic Virtual Machine Migration Algorithms Using Enhanced Energy Consumption Model for Green Cloud Data Centers" vol 978-1-4799-5313, IEEE 2014

[5] Pradip D. Patel, M. D. Bhavsar, M. B. Potdar," Live Virtual Machine Migration Techniques in Cloud Computing", International Journal of Computer Applications, Volume 86 - No 16, January 2014.

[6] Zenon Chaczko, Venkatesh Mahadevan, Shahrzad Aslanzadeh, Christopher Mcdermid (2011)“Availabity and Load Balancing in Cloud Computing” International Conference on Computer vol.14 IACSIT Press, Singapore, 2011

[7] Srikantaiah S, Kansal A, Zhao F. Energy aware consolidation for cloud computing.Cluster Computing 2009;12:1-15.

[8] Mohammad Malekloo and Nadjia Kara, "Multiobjective ACO Virtual Machine Placement in Cloud Computing Environments" Workshop- Cloud computing Systems, Network and Applications,IEEE vol-10, 2014.

[9] A.Gandhi,M. Harchol-Balter, R. Raghunathan, and M. A. Kozuch, "AutoScale: Dynamic, robust capacity management for multi-tier data centers," ACM Trans. Comput. Syst., vol. 30, no. 4, pp. 1-26, 2012.

[10] Vidya Chachar and Prof. Nandakumar Kulkarni, "Resource Utilization Algorithm for Green Cloud Computing with Global Collaboration", Cyber Times International Journal of Technology \& Management, vol. 7, Issue 1,pp 560-564, Mar-2014

[11]L. Deboosere, B. Vankeirsbilck, F.Turck, P.Simoens, B. Dhoedt, and P. Demeester, "Efficient resource management for virtual desktop cloud computing," vol.62,no.2,pp.761-767, May 2012. 